\title{
An empirical study on the effects of industrial clusters on small and medium enterprises
}

\author{
Mojtaba Javidnia $^{\mathrm{a}^{*}}$, Ahmad tavangar ${ }^{\mathrm{b}}$, MohammadAli Astanbous ${ }^{\mathrm{b}}$ and Zeinab Armoun ${ }^{\mathrm{c}}$
}

${ }^{a}$ Department Of Management, Young Researchers Club, Semnan Branch, Islamic Azad University, Semnan, Iran

${ }^{b}$ Graduate Student of Industrial Management, Department of Management, Semnan Branch, Islamic Azad University, Semnan, Iran

${ }^{c}$ Master of Science, Department of management, Mashhad Ferdowsi University, Faculty of Administrative Sciences \& Economic, Mashhad, Iran

\section{ART I C L E I N F O}

\section{Article history:}

Received March 26, 2012

Accepted 15 June 2012

Available online

June 162012

Keywords:

Industrial cluster

Competitiveness advantage

Economical growth

DEMATEL fuzzy technique \begin{abstract}
A B S T R A C T
Tendency to industrial clustering at the end of the twentieth century was a turning point in industrial development programs in most countries of the world. Industrial clustering is a model of industrial organization, which has entered industrial literature as a new development strategy. Clustering has provided utilization of efficiencies of scale and aggregation as well as efficiencies of collective efforts by creating conditions for competitiveness advantage, economical growth and export development in the international environment. Today, industrial clustering has been considered as a fundamental strategy for economic development and growth in almost all countries of the world including Iran. This paper aims to assess and to explain important factors affecting the competitiveness of industrial clusters. It also shows the relationship among these factors together. The proposed study uses fuzzy DEMATEL technique; hence, the affecting factors of competitiveness of industrial clusters in the automotive cluster in one of the provinces of Iran is investigated and the importance of each of these factors and their relationships are identified.
\end{abstract}

\section{Introduction}

Auto parts manufacturing industry has some relative advantages such as competitive price mainly because of cheap and skilled labor. This industry plays an important role in Iranian non-oil-export and many people are interested in investing in this industry since it needs low capital for establishing small and medium enterprises of auto parts manufacturing. During the past few years, there have been many companies entered into auto parts manufacturing industry and this has led to more intense competition in this industry. Nowadays, small and medium enterprises are extremely important in developing countries (Khodami, 2009). In fact, a high share of industrial firms worldwide is dedicated to small and medium enterprises and considering the undeniable role of these firms especially in some of economic indicators including the share of export and added value of production in industrial countries, the economists' focus has led from large industrial enterprises to the small and medium enterprises. Given the vital role of the small and medium enterprises can play

* Corresponding author. Tel: +989122313702

E-mail addresses: mojtaba.javidnia@yahoo.com (M. Javadinia) 
in economic development of the country and also the advantages they have compared to large companies, attention to strengthening and development of such competitive industry seems necessary (Mottaghi, 2011).

In this regard and in order to boost development of small and medium enterprises, Porter (1998), proposed another type of approach in analyzing issues related to small and medium enterprises. The method considers the placement of economic enterprises along and within each other and their horizontal and vertical relationships as well as interaction with national and international bodies and all involved factors in the producing process, are examined as a whole called "cluster". The cluster analysis framework provides us a new possibility for economic study of the regions, in which the role and the impact of each factor in an economic environment, could be easily perceived. This way, each firm, becomes a small unit of a large producing network. This is a good idea to increase competitiveness capability of the small and medium enterprises and the industrial clusters can be easily placed in added-value chain and the global trade through usage of gains and positive economic external effects. There is a competition inside the industrial clusters and clusters can penetrate in a more advanced form into the international market. In this paper, we study the factors effective on competitiveness of industrial clusters and its impact on competitiveness capability of the small and medium auto parts manufacturers in one of the provinces of Iran.

\section{Literature and background of the research}

Porter (1998) conducted a field and library study in the American industrial clusters level and described their structure. Porter showed that clusters are consisted of a group of related companies, professional suppliers, service providers, enterprises of interdependent industries and bodies connected to each other. This set is active in a common field and concentrated in a certain geographical area. Then, another study in 2000 concluded that clusters contain a large amount of skill, intelligence, relationships and infrastructures in a particular field.

During their case studies on both traditional and modern clusters in Sweden, Person and Ceccato (2002) announced that congestion of plants in one place is a way for development and maintenance of privileges of competitive economy.

Dewitt et al. (2006) examined the linkage among porter's cluster theories and supply chain management and the positive effects of competition on companies' performance using the data resulted from a case study in Amish furniture industry in Ohio of the United States. They found out that the geographical focus of the cluster has a positive effect on the supply chain and increases the competitive advantage.

Roveda and Vecchiato (2006) conducted filed and library study of industrial clusters in some important industrial areas of Italy. The main objective of this study was to describe and to evaluate the role of prediction for nurturing innovation capability of industrial cluster so that innovation in processed and products are essential. Forecasting in industrial areas indicated that progress plays an important role in creation and exploitation of new knowledge. Innovation is the required principal for confronting challenges of global competition. The presented cases show that forecasting is a valuable tool for promoting innovation in industrial fields and supports development and diffusion of new technology among local companies.

Boja (2011) studied concepts of industrial clusters and competitive advantage, which starts at economic analysis and continues with Porter's initial studies. This scholar in his research mentioned that industrial clusters are very important as a competitive field in many businesses and simultaneously in competition and cooperation for obtaining various economic advantages. In this study the determinants of industrial clusters and their features are determined and analyzed through questionnaire and as a result a summary of the main features are obtained and a model of industrial 
cluster determinants was described. The ultimate aim of this paper is highlighting the importance and advantages of use of industrial clusters and their determinants.

\section{Literature review}

\subsection{Small and medium enterprises}

In most countries, small and medium enterprises (SMEs) constitute more than 95\% of the manufacturing and industrial companies and provide two third of the industrial employment in the private sector. In recent years, these enterprises have had special place in Iranian economy and hence they have become the subject of many researches and studies. There are various identifications of small and medium enterprises. Some people identified small and medium organizations as the ones that have fewer than 250 employees and others believe that these companies have fewer than 500 employees (Beck et al., 2005). Based on European Union's criteria, the small and medium industries are identified according to their numbers of employees and the amount of annual capital flow. Accordingly, the number of these companies' employees is fewer than 250 and their working capital should not exceed 40 million Euros (Kim et al., 2006).

In Iran, the number of employees is the only factor in assessing SMEs and a firm with fewer than 50 employees is considered as small industry, a firm with 50 to 150 employees is a medium industry and any firm with more than 150 employees is considered as a large industry (Amin Bidokhti, 2010). Iranian Central Bank also considers businesses with fewer than 100 employees as small and medium, yet according to studies of business research center and small and medium industry's development organization and current regulations of Iran, firm sets with fewer than 50 personnel are among the small and medium enterprises.

\subsection{Industrial Clusters}

Creating job opportunities requires setting up and developing production and service activities and also increases in production depends on more usage of production factors including capital. Hence, any planning and employment policy should be based on accurate identification of problems and production and investment barriers. Organizing industries in the form of networks and industrial and manufacturing clusters to improve competitive capability, efficiency and participation in regional and global arenas in most countries in the world has had impressive economic results. If such programs are implemented, effective steps in line with the national employment booming and economic development will be taken. There are a lot of identifications for industrial clusters. According to Maskell (2001), the word cluster is used as a synonymous with industrial aggregation or concentration in the literature, while the word industrial areas is used where target is to expressly refer to values and norms resulted from proximity. Horizontal dimensions of the clusters expand when gains from regionalism exists which are independent from the amount of internal interaction of enterprises. In this case, conducting similar activities in the circumstances that they are adjacent to each other is required and the vertical dimension of the clusters spreads only with the increase in the number of active firms in the cluster.

Industrial cluster is generally a combination of various theories like economic geographic theory, regional economy, national innovation system, knowledge theory transfer, social capital theories and social networks. In the latest definition, Porter (1998) defined cluster as geographic concentration of bodies and related companies in a specific field. Thus, according to Porter (1998), clusters consist of a collection of related companies, professional suppliers, service providers, firms of the interdependent industries and institutions linked together such as universities, standard institutes and trade associations. This set is an active in a common area and is concentrated in a certain geographic confine. Clusters affect competition through the following three ways: 
$\checkmark$ By increasing efficiency based on the location of the companies

$\checkmark$ By rapid directing of development of the innovations that ensure the future productivity growth

$\checkmark$ By encouraging formation of new businesses which develops and strengthens the cluster

Each cluster allows its member to act in such a way to become larger and it can join to other companies without losing the flexibility (Porter, 1998). So, what cause clusters to be of interest to policy makers is the opportunities of collective efficiency, which come from external economic gains, low trading costs and collective action. Therefore, the mere spatial concentration of companies that have no connection to each other cannot increase the collective efficiency, and these are interactions and external effects, which are of interest. Therefore, we can say that industrial clusters are common in two factors of geographical concentration of enterprises and alignment of the units in a specific added value.

\subsection{Competitiveness capability}

The global village is getting smaller every moment and those remain who have more competitiveness, a competition for survival and better living. Therefore, in recent years, competitiveness has come into attention in many countries of the world. In competitiveness definition, it can be stated that, competitiveness is a country's or an industry's economic capability for stabilizing or increasing its share in the international market. Development management institution, defines national competitiveness as governments' performance in establishment and maintaining the environment in which they compete (IMD, 2005). From UNIDO's point of view also, clustering help small and medium enterprises combine their powers to obtain advantage of market opportunities and to solve common problems through a joint action. Therefore, inter-cooperation between small and medium enterprises allows them to improve their competitiveness and reach for superior opportunities in global market (UNIDO, 2003).

\subsection{Semnan province's auto parts industrial cluster}

Semnan province's auto parts industrial cluster is counted as the second standard and specific for automation parts manufacturer in Iran, which has reached significant progresses through connecting to global supply chain and obtaining international quality certifications, increasing technologic and skill levels of skilled and specialist work force and maximum use of production capacities. This cluster consists of 123 small and medium automotive parts manufacturers in industrial town of Semnan province where 108 companies are the main automotive parts manufacturers and others are beneficiaries of the cluster, which provides business development services (BDS). The raw material suppliers and machinery tools vendors, marketing and sales companies, intermediaries, educational bodies and institutes, financial and service units are associated with and are sub-contractors of this cluster. Some of the major products of the companies in the cluster include the fuselage and outer parts, electric and electronic components, assemblies, driveline and chassis, engine and equipment maintenance accessories.

\section{Research Methodology}

\subsection{DEMATEL}

DEMATEL was first introduced at Battelle Memorial Institute of Geneva Research Center. This method was applied in relation to complicated problems of the world such as famine, energy, environmental protection, etc. (Fontela \& Gabus, 1976). DEMATEL is one the multi criteria decision making instruments and has the ability to convert the qualitative designs to the quantitative analysis (Lee et al., 2011). The aim of DEMATEL is to convert the relation between criteria, causal dimensions from a complex system to an understandable structural model of that system (Dalalah et al., 2011). All criteria of a particular system, directly or indirectly, are mutually associated with each 
other in a general reciprocal system. So each change in one of criteria will influence on other criteria (Tzeng et al., 2007). This technique is successfully applied in other circumstances such as development methods, management systems, electronic learning evaluation, knowledge management, etc. (Kuoa \& Liang, 2011). Japan, Korea and Taiwan have widely used DEMATEL technique for successful solving of different problems in different fields (Lin \& Wu, 2008).

\subsection{Fuzzy-logic}

Many organizations accepted group decisions to find a solution. Group decision means to achieve an agreement through dialogue among many experts and in this case, an acceptable decision can be adopted. Of course, in the decision related to complex systems, assessment by experts or decisionmaker about a qualitative criteria object will be presented, always couched in language (and not in the form of determined quantities) and based on their experience and skills. Therefore, the theory of fuzzy collection can be used to measure ambiguous concepts based on unreal (personal) judgments. Based on Table 1, we can change the vague judge to fuzzy triangle numbers.

\section{Table1}

The correspondence of linguistic terms and values

$\begin{array}{cccccc}\text { Linguistic values } & {[0.75,1,1]} & {[0.5,0.75,1]} & {[0.25,0.5,0.75]} & {[0,0.25,0.5]} & {[0,0,0.25]} \\ \text { Linguistic terms } & \text { Very high influence(VH) } & \text { High influence(H) } & (\mathrm{L}) \text { Low influence } & \text { Very low influence (VL) } & \text { No influence (NO) }\end{array}$

Fuzzy triangle number can be a regular triplets (l, $m, n)$ represented as $1 \leq \mathrm{m} \leq \mathrm{n}$. For both fuzzy triangle numbers $A_{1}=\left\{l_{1}, m_{1}, r_{1}\right\} A_{1}=\left\{l_{2}, m_{2}, r_{2}\right\}$, the following shows arithmetic operations

$$
\begin{array}{ll}
A_{1}+A_{2}=\left(l_{1}+l_{2}, m_{1}+m_{2}, r_{1}+r_{2}\right) & A_{1}-A_{2}=\left(l_{1}-l_{2}, m_{1}-m_{2}, r_{1}-r_{2}\right) \\
A_{1} \otimes A_{2}=\left(l_{1} l_{2}, m_{1} m_{2}, r_{1} r_{2}\right) & \lambda A_{1}=\left(\lambda l_{1}, \lambda m_{1}, \lambda r_{1}\right),(\lambda>0)
\end{array}
$$

Since the fuzzy numbers are not directly suitable for matrix operations, for more accumulation, defuzzy algorithm is needed where the fuzzy nonmembers will be changed to real numbers. In recent years, different types of defuzzy methods have been developed (Opricovic \& Tzeng, 2003). In the meantime, the especial unknown and instable environment where fuzzy numbers are used should be considered by selecting the defuzzy technique. The proposed model of this paper uses the defuzzy, santroid, (the center of gravity) proposed by Yager and Philo (1994), which is usually used (Kanter, 1985). However, this method is not able to differentiate between two fuzzy numbers with different forms, which are changed to a determined numbers, using this method (Kouriloff, 2000). In this study, we use the method called changing the fuzzy data into determined values (CFCS), which was proposed by Opricovic and Tezeng (2003) to defuzzy the numbers. In CFCS method, first, right and left values are determined with a minimum and maximum fuzzy based on the fuzzy numbers based on group evaluation and then the final definite number are calculated in terms of average weight based on membership subject.

\subsection{The Fuzzy DEMATEL`s steps}

1.We specify evaluation factors according to expert committee’s opinions and research background.

2.We determine each factor influences on whole system, according to expert's opinion. To do so, we use discussed wordy expressions in Table2 and Fig 1. Then, we used CFC method (Eq. (1) to Eq. (9)) to convert the fuzzy results into crisp value.

Table 2

The correspondence of linguistic terms and values

\begin{tabular}{cccccc}
\hline Linguistic values & {$[0.75,1,1]$} & {$[0.5,0.75,1]$} & {$[0.25,0.5,0.75]$} & {$[0,0.25,0.5]$} & {$[0,0,0.25]$} \\
\hline Linguistic terms & $\begin{array}{c}\text { Very high } \\
\text { influence( }(\mathrm{VH})\end{array}$ & High influence(H) & Low influence (L) & $\begin{array}{c}\text { Very low } \\
\text { influence (VL) }\end{array}$ & No influence (NO) \\
\hline
\end{tabular}




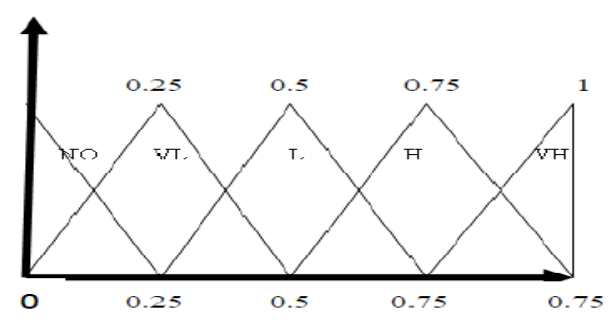

Fig. 1 . Fuzzy triangle numbers

$$
\begin{aligned}
& \mathrm{XL}_{\mathrm{ij}}^{\mathrm{k}}=\left(\mathrm{L}_{\mathrm{ij}}^{\mathrm{k}}-\underset{1 \leq \mathrm{k} \leq \mathrm{k}}{\operatorname{minL}_{\mathrm{ij}}^{\mathrm{k}}}\right) / \Delta_{\min }^{\max } \\
& \mathrm{XM}_{\mathrm{ij}}^{\mathrm{k}}=\left(\mathrm{M}_{\mathrm{ij}}^{\mathrm{k}}-\operatorname{minL}_{1 \leq \mathrm{k} \leq \mathrm{k}}^{\mathrm{k}}\right) / \Delta_{\min }^{\max } \\
& \mathrm{Xr}_{\mathrm{ij}}^{\mathrm{k}}=\left(\mathrm{r}_{\mathrm{ij}}^{\mathrm{k}}-\underset{1 \leq \mathrm{k} \leq \mathrm{k}}{\operatorname{minL}_{\mathrm{ij}}^{\mathrm{k}}}\right) / \Delta_{\min }^{\max } \\
& \Delta_{\min }^{\max }=\operatorname{maxr}_{\mathrm{ij}}^{\mathrm{k}}-\operatorname{minL}_{\mathrm{ij}}^{\mathrm{k}} \\
& X s_{i j}^{k}=\frac{X m_{i j}^{k}}{\left(1+X m_{i j}^{k}-X l_{i j}^{k}\right)} \\
& \mathrm{Xrs}_{\mathrm{ij}}^{\mathrm{k}}=\frac{\mathrm{Xr}_{\mathrm{ij}}^{\mathrm{k}}}{1+\mathrm{Xr}_{\mathrm{ij}}^{\mathrm{k}}-\mathrm{Xm}_{\mathrm{ij}}^{\mathrm{k}}} \\
& X_{i j}^{k}=\left[\operatorname{Xls}_{i j}^{k}\left(1-X_{i j}^{k}\right)+\operatorname{Xrs}_{i j}^{k} \cdot \operatorname{Xrs}_{i j}^{k}\right] /\left(1+\operatorname{Xrs}_{i j}^{k}-X^{k} s_{i j}^{k}\right) \\
& \mathrm{BNP}_{\mathrm{ij}}^{\mathrm{k}}=\min L_{\mathrm{ij}}^{\mathrm{k}}+\mathrm{X}_{\mathrm{ij}}^{\mathrm{k}} \Delta_{\min }^{\max } \\
& \mathrm{a}_{\mathrm{ij}}=\frac{1}{\mathrm{k}} \sum_{\mathrm{k}}^{1 \leq \mathrm{k} \leq \mathrm{k}} \mathrm{BNP}_{\mathrm{ij}}^{\mathrm{k}}
\end{aligned}
$$

$\mathrm{A}=\left[\mathrm{a}_{\mathrm{ij}}\right]$ is direct relations matrix of experts opinions.

3. Obtain total relations matrix T-I, where I is identity matrix $n \times n$ and elements of $T=\left[t_{i j}\right]$ indicate the direct and indirect influences of factor $i$ on factor $j$. Matrix $\mathrm{T}$ can be an indicator of general relationships between each pair factor in the system. Matrix D is the normalized matrix. $D=\left[d_{i j}\right]$, $0 \leq d_{i j} \leq 1$.

$$
D=\frac{1}{\max _{1 \leq i \leq n} \sum_{j=1}^{n} a_{i j}} A
$$

$T=D(I-D)^{-1}$

4. Calculate the row summation and the column summation of matrix $T$ matrix where $i^{\text {th }}$ row summation is indicator of all direct and indirect influences of $i^{\text {th }}$ factor on all other factors and so we 
can call $r_{i}$ as the influencing degree. $C_{j}$ is similarly, the column summation and we can call it as influenced degree of $j^{\text {th }}$ factor.

$$
\begin{aligned}
& r_{i}=\sum_{1 \leq i \leq n} t_{i j} \\
& C_{j}=\sum_{1 \leq i \leq n} t_{i j}
\end{aligned}
$$

Therefore, when $i=j, r_{i}+C_{i}$ shows both the influence that $i^{\text {th }}$ factor can have on other factors of system and also the influences of other factors of system on $i^{\text {th }}$ factor. So, $r_{i}+C_{i}$ show the significant degree of $i^{\text {th }}$ factor in whole system, and $r_{i}-C_{i}$ indeed shows the influence of $i^{\text {th }}$ on system. If $r_{i}-C_{i}$

is positive, $i^{\text {th }}$ factor belongs to the cause group and if $r_{i}-C_{i}$ is negative, $i^{\text {th }}$ factor belongs to the effect group.

5.Finally, We show the diagram of factors influencing on $r_{i}-C_{i}$ and $r_{i}+C_{i}$ bases. This diagram is drawn by $\left(r_{i}+C_{i}, r_{i}-C_{i}\right)$ coordinate to Huang (2009).

\subsection{Using Fuzzy DEMATEL}

In this study, first, using the ideas of experts and activists of the industry as well as referring to related resources and references, 6 effective factors on competitiveness of industrial clusters are defined. Then, by distributing questionnaires among 5 senior managers who are active in the industrial cluster of auto part in Semnan province and by assistance of the DEMATEL and Fuzzy logic, the effects of important factors on each others are carefully analyzed. Factors affecting the competitiveness of industrial clusters are as follows and they are briefly shown in the Fig. 2.

1. Resources: by Resources, we mean the natural or developing capacities, which exist within the region and they include skilled, flexible and affordable workforce, strategic geographical location, financial capital and technology.

2.Infrastructure: infrastructures include physical structures and institutional arrangements, which facilitate access to resources and performances of other businesses and they are consisted of physical infrastructures such as roads, ports and communication equipments as well as institutional infrastructures such as business associations, research laboratories, educational systems, taxing system, monetary and fiscal policies.

3.Supply companies related to cluster: the success factors in this regard include diversity, quality, cost and efficiency of suppliers related to cluster as well as the quality of customer-supplier relations.

4.Structures, strategies and competition within a cluster: the objective evaluating companies are directly in value chain for product line. Their evaluation can be done by questions such as "are they well organized? How safe are they? How reliable are they? How fast are they? It can also include measurable indicators such as number and size of the companies and their ownerships and financial strengths. This evaluation also includes competitive strategies and growth.

5.Access to domestic market: by domestic market we mean markets within the region. The important issues include the size of the market, growth and prospect, local resources development by customers and satisfaction of the customers for working with the local cluster.

6.Access to foreign markets: in general, the cluster areas, more or less are facing with the foreign markets. What distinguishes between areas is accessibility and it includes issues such as proximity of 
1972

markets, their size and growth, the cluster's global market share, the existing relations in the market, barriers of entry and barriers of trade and export.

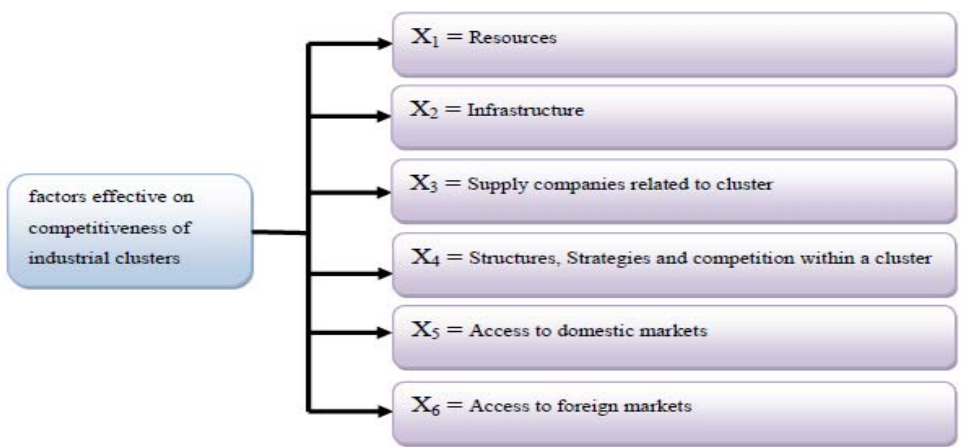

Fig 2 . Factors effective on competitiveness of industrial clusters

Note that the experts used the expressions in Table 1 to fulfill the questionnaire. Matrix of direct relations (A) in Table 3 and General relations matrix (T) in Table 4 are shown as follows,

\section{Table 3}

Direct relations matrix (A)

\begin{tabular}{lcccccc}
\hline Factor & $\mathrm{B}_{1}$ & $\mathrm{~B}_{2}$ & $\mathrm{~B}_{3}$ & $\mathrm{~B}_{4}$ & $\mathrm{~B}_{5}$ & $\mathrm{~B}_{6}$ \\
\hline $\mathrm{B}_{1}$ & 0 & 0.511 & 0.004 & 0.004 & 0.004 & 0.11 \\
$\mathrm{~B}_{2}$ & 0.888 & 0 & 0.004 & 0.004 & 0.499 & 0.888 \\
$\mathrm{~B}_{3}$ & 0.004 & 0.004 & 0 & 0.11 & 0.004 & 0.004 \\
$\mathrm{~B}_{4}$ & 0.004 & 0.004 & 0.422 & 0 & 0.288 & 0.004 \\
$\mathrm{~B}_{5}$ & 0.004 & 0.238 & 0.004 & 0.004 & 0 & 0.004 \\
$\mathrm{~B}_{6}$ & 0.625 & 0.499 & 0.957 & 0.957 & 0.819 & 0 \\
\hline
\end{tabular}

\section{Table 4}

General relations matrix -T Matrix

\begin{tabular}{lcccccc}
\hline Factor & $\mathrm{B}_{1}$ & $\mathrm{~B}_{2}$ & $\mathrm{~B}_{3}$ & $\mathrm{~B}_{4}$ & $\mathrm{~B}_{5}$ & $\mathrm{~B}_{6}$ \\
\hline $\mathrm{B}_{1}$ & 0.045 & 0.149 & 0.019 & 0.018 & 0.035 & 0.064 \\
$\mathrm{~B}_{2}$ & 0.292 & 0.085 & 0.073 & 0.068 & 0.201 & 0.258 \\
$\mathrm{~B}_{3}$ & 0.002 & 0.002 & 0.004 & 0.029 & 0.004 & 0.002 \\
$\mathrm{~B}_{4}$ & 0.003 & 0.007 & 0.111 & 0.004 & 0.077 & 0.003 \\
$\mathrm{~B}_{5}$ & 0.019 & 0.067 & 0.006 & 0.006 & 0.013 & 0.017 \\
$\mathrm{~B}_{6}$ & 0.212 & 0.181 & 0.290 & 0.269 & 0.267 & 0.049 \\
\hline
\end{tabular}

The total of the given effects and receiving effects of the factors (cause and effect matrix) and the graph of the effect of the factors were respectably shown in Table 5 and Fig. 3.

Table 5

Calculating the influences of each factor

\begin{tabular}{ccccc}
\hline Factor & $r_{i}$ & $C_{i}$ & $r_{i}+C_{i}$ & $r_{i}-C_{i}$ \\
\hline $\mathrm{B}_{1}$ & 0.330 & 0.573 & 0.903 & -0.243 \\
$\mathrm{~B}_{2}$ & 0.977 & 0.490 & 1.467 & 0.487 \\
$\mathrm{~B}_{3}$ & 0.041 & 0.503 & 0.544 & -0.462 \\
$\mathrm{~B}_{4}$ & 0.204 & 0.393 & 0.597 & -0.189 \\
$\mathrm{~B}_{5}$ & 0.128 & 0.596 & 0.724 & -0.468 \\
$\mathrm{~B}_{6}$ & 1.268 & 0.393 & 1.660 & 0.875 \\
\hline
\end{tabular}




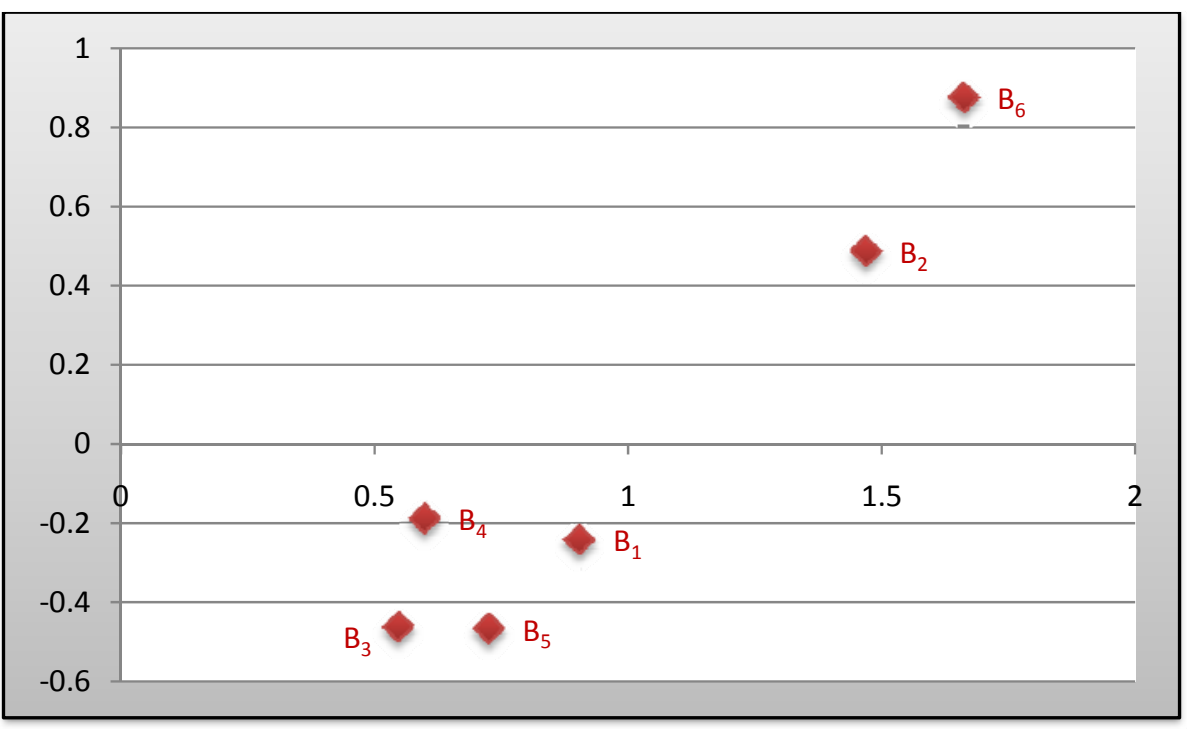

Fig.3. The casual diagram

\section{Conclusion}

In this study, we examined the factors effective on competitiveness of industrial clusters and their effects on competitiveness capability of small and medium companies existing in the industrial cluster of Semnan province's automotive parts and based on results of using DEMATEL fuzzy method, we categorized effective factors based on competitiveness of industrial clusters in two effective factors and impressible factors. The results showed that the most effective factors are access to foreign markets and infrastructures, respectively. In addition, the most impressible factors include supply companies are related to cluster, access to domestic market, resources and structures, strategies and competition within a cluster.

In summary, it can be stated that a sustainable development strategy for directing small and medium companies towards competitiveness is to develop principles of industrial cluster. Threads such as small companies can be removed by development of a cluster based on collective efficiency and geographical concentration and by establishment of a set of interactions and using common opportunities. In this regard, deployment of the private sector and specialization to increase competitive capability of automotive parts manufacturers in domestic and foreign markets provide effective solution in line with development of the industrial clusters of auto parts for the decision makers of the industry.

At the end, in order to provide a general solution, it can be stated that the factor of basic investment in small and medium companies is a major factor in economic development of Semnan province and industrial cluster of auto parts. It includes a set of small and medium industries and service enterprises in an industrial field, which can provide preparation for identification of the relative capacity of Semnan province in investment compatible with regional capacity by using appropriate knowledge and technology.

Considering the existence of automotive parts industries, the product quality can be increased and final cost can be optimized by more specialization of products of auto parts cluster by construction the necessary equipments and parts of the automotive industry. This optimization ultimately affects other sectors and causes better presence of industry's products in global market and on the other hand it provides the internal development and growth of the province in different fields including employment, per capital income etc., which ultimately leads to competitiveness capability in this industrial cluster. 


\section{References}

Amin Beidokhti, A. (2010). The role of industrial small and medium enterprises (SMEs) in creating entrepreneurship opportunities. Excavations Journal of Business Administration, 1(2), 171-190.

Beck, R., Wigand, R. T., \& Konig, W. (2005). Integration of E-Commerce by SMEs in the manufacturing sector: A data envelopment analysis approach. Journal of Global Information Management 13(3), 20-32.

Boja, C. (2011). Clusters Models, Factors and Characteristics. International Journal of Economic Practices and Theories, Academy of Economic Studies - Bucharest, 1(1), 34-43.

Dalalah, D., Hayajneh, M., Batieha, F. (2011). A fuzzy multi-criteria decision making model for supplier selection. Expert Systems with Applications, 38, 8384-8391.

Fontela, E., \& Gabus, A. (1976). The DEMATEL observer. DEMATEL 1976 Report. Switzerland, Geneva: Battelle Geneva Research Center.

Huang, H. C. (2009). Designing a knowledge-based system for strategic planning: A balanced scorecard perspective. Expert Systems with Applications, 36(1), 209-218.

Kanter, R. M. (1985). Supporting innovation and venture development in established companies. Journal of Business Venturing, 1(1), 47-60.

Kim, K.S., Knotts, T.L., \& Jones, S.C. (2008).Characterizing viability of small manufacturing enterprises (SME) in the market. Expert Systems with Applications, 34(1), 128-134.

Khodami, S. (2009). The effect of Internet on orientation of export channels in small and medium producing companies, supervisor Parviz Ahmadi, $\mathrm{PhD}$ thesis, International Marketing Management, Tarbiat Modarres University.

Kouriloff, M. (2000). Exploring perceptions of a priori barriers to entrepreneurship: a multidisciplinary approach. Entrepreneurship: Theory \& Practice, 25(2), 59-79.

Kuo, M.S. \& Liang, G. S. (2011). A novel hybrid decision-making model for selecting locations in a fuzzy environment. Mathematical and Computer Modelling, 54(1-2), 88-104

Lee, Y.C., Li, M.L., Yen, T.M., \& Huang, T.H. (2011). Analysis of fuzzy Decision Making Trial and Evaluation Laboratory on technology acceptance model. Expert Systems with Applications, 38(12), 14407-14416.

Lin, C. J., \& Wu, W. W. (2008). A causal analytical method for group decision-making under fuzzy environment. Expert Systems with Applications, 34(1), 205-213.

MirHosseini, S.V., \& Ghanbari , M.R. (2011). Investigation of the industrial clusters in Islamic Repub lic of Iran (C ase Study of Yazd city using local production systems method \& Industry Perception Model). International Journal of Academic Research in Business and Social Sciences, 1(3), 366-357.

Mottaghi, P. (2011). Modeling of successful management performance in small industry. PhD thesis on Human Resource Management. Tarbiat Modarres University.

Opricovic, S., \& Tzeng, G.H. (2003). Defuzzification within a multicriteria decision model. International Journal of Uncertainty, Fuzziness and Knowledge-based Systems, 11, 635-652.

Porter, M. (1998). Clusters and the new economics of competition. Harvard Business Review, 76(6), 77-90.

Roveda C., \& Vecchiato, R. ( 2008). Foresight and innovation in the context of industrial clusters: The case of some Italian districts. Technological Forecasting \& Social Change, 75, 817833.

Tzeng, G. H., Chiang, C. H., \& Li, C. W. (2007). Evaluating intertwined effects in elearning programs: A novel hybrid MCDM model based on factor analysis and DEMATEL. Expert Systems with Applications, 32, 1028-1044.

UNIDO (2003). Development of clusters and Networks of SMEs: The UNIDO programme a guide to export consortia. United Nations Industrial Development Organization, Vienna. 